\title{
Mobile Application for Obtain the Traffic Violations
}

\author{
Ali Abdulhussian Hassan \\ College of Education Pure Sciences, University of Karbala, Karbala, Iraq
}

\begin{abstract}
The evolution in the field of communication and information technology should overshadow on the various aspects of life, whether in the economic, education, health, police and other public services. Obtaining traffic violations as soon as possible would increase government revenue, and contributes to support the economy, especially those that rely on its economy on one source of income (economic rent). Most of the owners of cars do not pay traffic fines her time specified and this obscures great deal of money from the government in addition to the accompanying owing to the cancellation of financial corruption offenses after its edit by the field officers. In this paper, researcher designed an electronic program that helps the traffic police to obtain legal wages on traffic violations through the use of Android platform. The scope of this study is Karbala city border.
\end{abstract}

Keywords: traffic violation, traffic police, mobile application, fines.

\section{INTRODUCTION}

When The development in Internet has been turn out the major data and information provider from the time when its discovered at the last part of the 20th century. at this time, in the all area of the world, universities, the internet is considering the key generators and clients of information, according to the best of the worthy organizations which have able to Internet access at any time [1]. In addition, the Internet, a wide range of devices joined together with networks inside a one huge network to cover all over the world, and that represent the biggest network [2]. The emergence of internet and relevance services obtainable over the Internet have created awareness for strategic use of information for education and research [3], especially in the economic, education, health and police. According to Ani [4] the internet has become the most popularly used electronic information resources and services in all environments in the world, also its capabilities and its applications are becoming an important part in our live [5]. The issues which dealing in this paper, we did not have enough traffic police members and CCTV to cover all the area of Karbala city to issue the fine to the care that violate traffic laws, in addition, how can solve the case of delay obtaining an amount of money of traffic violations as soon as possible and that would increase government revenue, and contributes to support the economy, especially those that rely on its economy on one source of income (economic rent). Most of the owners of cars do not pay traffic fines her time specified and this obscures great deal of money from the government in addition to the accompanying owing to the cancellation of financial corruption offenses after its edit by the field officers.

So, we need to insert other factors to solve these issues, exactly there are two factors, first one, we should get a benefit from mobile technology and the other is insert the client (citizen who use the application) of city to help traffic police to cover the all the area of city. In this paper, researcher designs an application program that helps the traffic police to obtain legal wages on traffic violations through the use of Android platform. We plan to collected information exactly from a stakeholders within the traffic police management in Karbala city -Iraq, in addition from the projected clients of this application, according to traffic police officers, who were meet, that exact features and functions for mobile applications that should be derived in the definite use of the mobile applications in exact cases. The researcher founds that, whereas almost the stakeholders are not complex and approximately general in conditions of the functionalities which they require, for use the mobile is extremely based on the case in which traffic police cops have to run.

\section{LITERATURE REVIEW}

According to the previous study, most of the studies are about using the internet for violating the traffic or for send report about illegal actions. According to Harry et al [6], they designed mobile application system for police officers. Primary, they start from study of the functional and necessities of stakeholders and pertinent context parameters for police officers, they find that the design issues which are related to the improvement of situation conscious of mobile applications for police officers. Alkhateeb et al [7], use of position depended on services for develop and build up a system which can be used without difficulty to do a report and identify an accident extra rapidly and exactly. Another researchers, Michel MOREL \& Stéphane CLAISSE [8], they design a system to detect permanently in addition to track plus keep an eye on all category of the ship traffics, during danger trading lanes and regions so as to notice illegal or criminal vessel behaviour to recognize and early discover precursory cases 
Vol. 6, Issue 1, January 2017

and send reports tor that. In addition Bruce E. Higgins [9], process than other types of models and he designed system for monitoring and reporting can say, that be useful for a big of types of project [17]. In incidences of traffic violations at a traffic location is figure 1, we can illustrate the chosen methodology. The disclosed. The system comprises one or more digital still main reason for choosing this type of methodology that cameras and one or more digital video cameras system reflects backside to the relation between tasks and rapid of deployed at a traffic location, and Endarnoto et al [10] is prototyping [15], better parallelism, and the concurrency used the information extraction technicality to data in design with build activities [18]. in the meantime, this acquisition of traffic movement, in which, the traffic type of method is widely helpful in evaluating and movement information can be obtainable inside map view confirming the performance, quality, and level of software like a mobile application system of Android. Through from the near the beginning stage of development and in using Google Map, the taken away the information will be showed in 3 various colours to 3 various scale of traffic condition movement. In other article, Law et al [11] the mobile application has been design to modify the approach of people reports road accident, his system aim an interactive the mobile application that designed to modify the means of people report road accident suitcases by applying a convenience and simplicity rules, the client only needs to take photo picture for accident and click on screen for send the report. There is some study presented by Lan and Huang [12], The point of them purposed system was to mix the mobile communication technology with GPS to build a real time and suitable report of the mobile application network service system, and they called the Mobile Traffic Violation Reporting System (MTVRS), to get better learners' about traffic violation reflection level. In 2012, the paper of Wu et al [13], they suppose a mobile application system for Android smart phones which monitors that the taxi ease of use at taxi stands by MINING in real time taxi way gather with data streams and send report for stakeholders or user. as well as the traffic conditions in the area around the stand. Also altaee [14] designed a mobile application for illegal action, where that send report to security centre for illegal actions dependent on GPS in real time.

As mentioned earlier, and as shown in the studies above, most the studies are focused on reporting systems' development depending on internet environment. These include dealing with the Department of traffic police or emergency centers which did not exploit the advantage of using the Internet to reach the best services for get the fines, especially indifferent drivers. Also, recently, most policies of governments regarding the finance sector have changed, which has led to the change of its policies with all sectors. This study is trying to bridge this gap through the design of a system for communication between traffic police center and the Department of finance and inquire about any new information. In addition, an automatic alarm service will be developed, which will alert drivers those are not employees in government to pay the fines before the end of date.

\section{METHODOLOGY}

passing on and relaying center of software from the early phase to the next stage [19]. The spiral means must be still designed methodically, with motion and fulfilment recognized for each phase of the spiral.

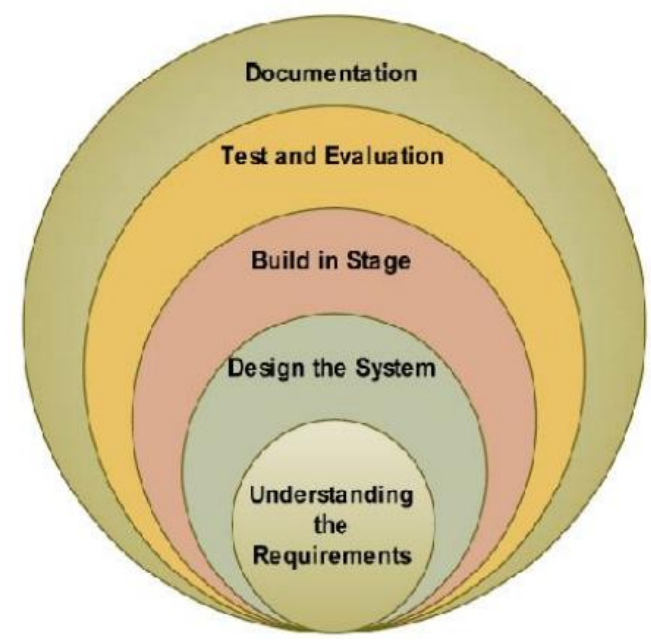

Fig. 1. Development of Spiral model by Barry [14]

3.1 Understand the Requirements

In this step is to collect the information for the goal system to identify the system. This step requires to understanding the ELECTRONIC SYSTEM TO OBTAIN FINES FOR TRAFFIC POLICE.

\subsection{Design the System}

According to the requirements of the ELECTRONIC SYSTEM TO OBTAIN FINES FOR TRAFFIC POLICE, it is designed to use the following languages to build the ELECTRONIC SYSTEM TO OBTAIN FINES FOR TRAFFIC POLICE : HTML \& C\#, SQL, Photoshop.

\subsection{Build in Stage}

In this step, the plan designer will try to evaluate the existing system in the same method as the earlier studies and appear with suitable application depend on the requirement gathered in the primary stage, and duplication the proceeding phase to reach a final result and build the system structure.

\subsection{Test and Evaluate}

The methodology method which will be use it in this paper In this step, the proposed ELECTRONIC SYSTEM TO is spiral type, Barry [15] has adopt this methodology. And OBTAIN FINES FOR TRAFFIC POLICE will be from a hazard driven of this approach [16], that is a extra thoroughly evaluated and tested. Routine maintenance is wide-ranging view of the design process and development carried out for the system. 


\subsection{Documentation}

Lastly, the study will be finished into document that includes the detailed of information about the project. Documentation can show in many forms, the majority universal one is a manual. The structure plan and study that will be described in document and the findings. The spiral type methodology is selected in this project that was adopted as mention above by Barry in 1988. This phase makes an introduction of the spiral methodology and explains its five phases or steps: first is understand the of requirements, second phase is design of the system, third phase is build in the stage, forth one is the test plus evaluate and finally is documentation phase.

\section{SYSTEM ANALYSIS AND DESIGN}
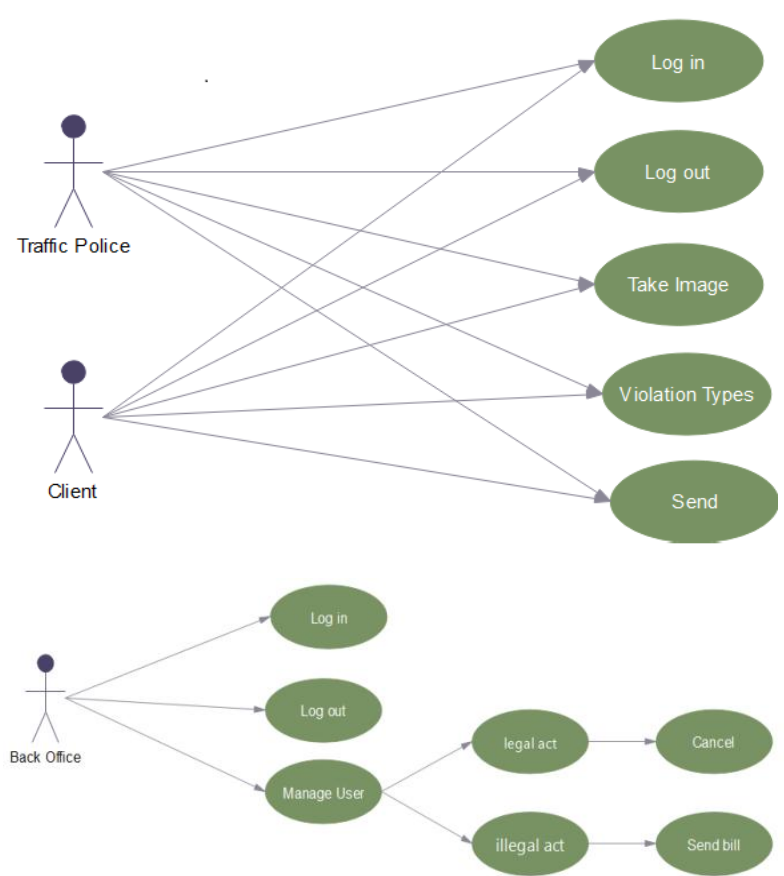

Fig. 2. Use case diagram for Electronic System to Obtain Fines for Traffic Police.

A use case defines a goal-oriented set of interactions between external actors and the system under consideration.

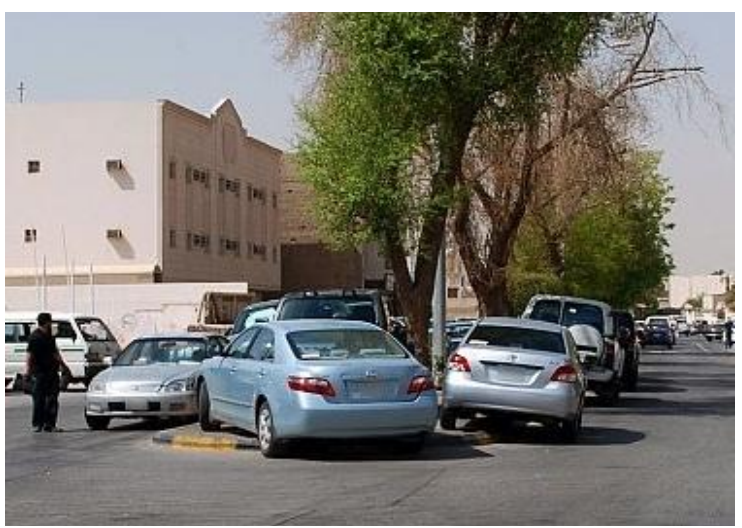

Fig. 3 Error parking.
Actors are parties outside the system that interact with the system. An actor may be a class of users, roles users can play, or other systems. Cockburn [20] distinguishes between primary and secondary actors.

This picture above, illustrate one of the violations types, that how the drivers parking into banned region and in wrong situation, and not found for any cameras or traffic police to issue the fine, so can the person which appear in the picture send report for police traffic center about this violations.

This system is a dedicated for both officer traffic and normal humans. Through it that the client can issue traffic violations in addition of course to the traffic cop. Where the user can (officer or client) take pictures through the program and sent to the database in the traffic center in real time. In turn, the centre works to evaluate the images and send the fine to the work place to owner that his car in violated the traffic law for deducted directly from his salary with send image for the violation and with locate the place by GPS, if the image that sent to centre need to give the fine. In the case was the owner of the car was not an employee, the traffic centre will send the details of the violation to the owner of the car through mobile phone networks and social networking sites and define deadline for the payment of the fine. The information centre in the traffic department should take all the details from the car owners, such as the workplace, telephone numbers, residential address and addresses social networking.

\section{CONCLUSION AND LIMITATION}

In this article the researcher aims to improve traffic sectors by use smart phone application, this system help the government to obtain the fines from the divers which do any illegal act, through some click on this application any one on the street can be a traffic police and send the report with a picture for the traffic violation to police traffic centre, this centre issue the bill for case that required to fine penalty.

There are some limitation in this application:

1- The government should put the law allow the traffic centre to get the fines from employee salary

2- Mobile should connect to internet through use this application.

\section{REFERENCES}

[1] A. P. D. B. E. ÖZAD and Ü. KUTOĞLU, "The use of the internet in media education," TOJET, vol. 9, 2010.

[2] B. Warf and J. Grimes, "Counterhegemonic discourses and the Internet," Geographical Review, vol. 87, pp. 259-274, 1997.

[3] G. Olasina, "A user requirement analysis of the internet resources by clients at cybercafés in Ibadan," The Information Technologist, vol. 3, pp. 30-9, 2006.

[4] O. E. Ani, "Internet access and use: A study of undergraduate students in three Nigerian universities," Electronic Library, The, vol. 28 , pp. 555-567, 2010.

[5] Talib, Mohammed Saad, and Zainab Saad Talib. "Simulate and Model MANET's Environment with AOMDV Routing 
Protocol." Oriental Journal of Computer Science \& Technology 7.1 (2014): 91-97.

[6] Bouwman, Harry, Timber Haaker, and Henny de Vos. "Mobile applications for police officers." BLED 2008 Proceedings (2008): 39.

[7] Alkhateeb, Faisal, et al. "The Use of Location Based Services for Very Fast and Precise Accidents' Reporting and Locating." Intelligent Systems, Modelling and Simulation (ISMS), 2010 International Conference on. IEEE, 2010.

[8] Morel, Michel, and Stéphane Claisse. "Integrated System for Interoperable sensors \& Information sources for Common abnormal vessel behaviour detection \& Collaborative identification of threat (I2C)." IEEE Conference publishing. 2010.

[9] Higgins, Bruce E. "Automated traffic violation monitoring and reporting system with combined video and still-image data." U.S. Patent No. 7,986,339. 26 Jul. 2011.

[10] Endarnoto, Sri Krisna, et al. "Traffic condition information extraction \& visualization from social media twitter for android mobile application." Electrical Engineering and Informatics (ICEEI), 2011 International Conference on. IEEE, 2011.

[11] Law, Foong Li, Zarinah Mohd Kasirun, and Chun Kiat Gan. "Gamification towards sustainable mobile application." Software Engineering (MySEC), 2011 5th Malaysian Conference in. IEEE, 2011.

[12] Lan, Yu-Feng, and Shin-Ming Huang. "Using mobile learning to improve the reflection: A case study of traffic violation." Educational Technology \& Society15.2 (2012): 179193.

[13] Wu, W., Ng, W. S., Krishnaswamy, S., \& Sinha, A. "To taxi or not to taxi?-enabling personalised and real-time transportation decisions for mobile users." Mobile Data Management (MDM), 2012 IEEE 13th International Conference on. IEEE, 2012.

[14] M.T.Omar \& A. Al-taee "E-report system for UUM security centre by using Smartphone technology ", 2014.

[15] B. W. Boehm, "A spiral model of software development and enhancement, " Computer, vol. 21, pp. 61 -72, 1988.

[16] C. Viravan, "Lessons learned from applying the spiral model in the software requirements analysis phase," in Requirements Engineering,

1997., Proceedings of the Third IEEE International Symposium on, 1997, p. 40

[17] G. Wolff, "The management of risk in system development:'project sp'and the 'new spiral model'," Software Engineering Journal, vol. 4 , pp. 134-142, 1989

[18] B. Boehm and P. Bose, "A collaborative spiral software process model based on theory W," in Software Process, 1994.'Applying the Software Process', Proceedings., Third International Conference on the, 1994, pp. 59-68.

[19] N. Yamamichi, T.-a. Ozeki, K. Yokochi, and T. Tanaka, "The evaluation of new software developing process based on a spiral modeling," in Global Telecommunications Conference, 1996. GLOBECOM'96.'Communications: The Key to Global Prosperity, 1996, pp. 2007-2012.

[20] A. Cockburn, "Structuring Use Cases with Goals1," 1997.

\section{BIOGRAPHY}

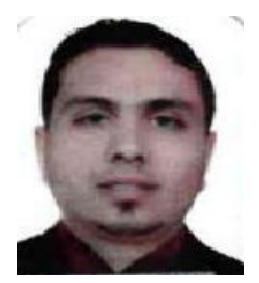

Ali Abdulhussian haasan received the B.S. and M.S. degrees in Communication Engineering from Technical College in 2004 and Information Communication Technology from University Utara Malaysia in 2014, respectively. During 2005-2012, he stayed in Communications Computer Research Laboratory in Electrical and Computer department. He now with College of Education Pure Sciences staff. 